\title{
The challenge of diagnosing childhood tuberculosis in a developing country
}

\author{
Connie M Osborne
}

Tuberculosis in children and adults is a growing problem with important public health implications. The global magnitude as well as trends of incidence, morbidity, and mortality of tuberculosis in children have remained unclear due to a lack of a definitive diagnostic tool in most of the cases.

Of the 21000 new cases notified in Zambia in 1991, approximately 2100 were children aged under 14 years (National Tuberculosis and Leprosy Program, Zambia, personal communication). Children under the age of 14 years constitute about $49 \%$ of the 8.6 million estimated population in the country. By comparison, in the USA which has an estimated population of 255 million, 23000 new cases of tuberculosis occur every year and approximately 1200 are children. ${ }^{1}$ Paediatric tuberculosis notifications, particularly in developing countries, may be an underestimate of the true incidence because of diagnostic constraints and poor reporting and notifying systems.

Although tuberculosis does not appear to be a major cause of paediatric hospital morbidity and mortality in Zambia, its contribution to childhood morbidity and mortality may be hidden under leading causes such as 'pneumonias, malnutrition and diarrhoea'. In Zambia, pneumonia is the number one cause of death in infancy excluding perinatal deaths. ${ }^{2}$ The aetiology of chronic pneumonias that we see in HIV infection is not known. While the index of suspicion for 'suspected' tuberculosis cases is high among Zambian paediatricians, the actual number of 'probable' paediatric tuberculosis cases, for example at the University Teaching Hospital (UTH), is only $2-3 \%$ of total paediatric admissions (UTH, paediatric service records 1989 to 1993 ).

The rise of tuberculosis in adults as a direct result of the HIV epidemic is expected to be paralleled by a similar rise of tuberculosis in children. At Lusaka's UTH, HIV seroprevalence rates in children with probable tuberculosis have risen from $24 \%$ in 1989 to $37 \%$ in $1990,56 \%$ in $1991,61 \%$ in 1992 , and over $70 \%$ in 1993 (G J Bhat, unpublished). ${ }^{3}$

This paper discusses the continued diagnostic challenge of paediatric tuberculosis in developing countries with particular reference to Zambia.

\section{Conventional diagnosis of tuberculosis in children}

Nearly all children in Zambia, as in other developing countries, are at risk of tuberculosis from infected adults. Primary infections occur mainly in infants and small children who are particularly prone to severe and disseminated forms of the disease. In contrast, children at risk of tuberculosis infection and/or disease in developed countries include inner city children, children of racial/ethnic minority groups, and foreign born children. ${ }^{4}$ Unfortunately, diagnosis of tuberculosis in children continues to rely heavily on clinical and epidemiological grounds and from a diagnostic point of view, this has been classified into suspected, probable, and confirmed.

\section{SUSPECTED TUBERCULOSIS}

Tuberculosis is suspected when an ill child has a history of chronic illness that includes a cough and/or fever, weight loss or failure to thrive, an inability to return to normal health after measles or whooping cough, and history of contact with an adult case of pulmonary tuberculosis.

On physical examination there may be one or more of the following: malnutrition, lymphadenopathy, chest signs, hepatomegaly and/or splenomegaly, meningeal signs, and/or ascites. In areas of high prevalence of tuberculosis, HIV and malaria, the possibility of dual disease (tuberculosis and HIV or tuberculosis and malaria) or triple disease (tuberculosis, HIV, and malaria) should always be considered.

\section{PROBABLE TUBERCULOSIS}

Tuberculosis becomes probable when a child suspected of having tuberculosis has in addition to the above features any one of the following: a positive tuberculin skin test, suggestive chest radiological appearances (hilar adenitis, miliary shadows, consolidation, and/or pleural effusion), suggestive histological appearance of biopsy material (caseation), a poor response to two weeks of appropriate antibiotics and/or a favourable response to a trial of antituberculosis treatment (that is weight gain and disappearance of signs and symptoms).

\section{CONFIRMED DISEASE}

Isolation of Mycobacterium tuberculosis bacilli in 
Table 1 Diagnostic pathways for children with suspected tuberculosis at UTH

\begin{tabular}{|c|c|c|}
\hline \multicolumn{2}{|c|}{$\begin{array}{l}\text { Suspected tuberculosis } \\
\text { Ill child + suggestive history } \\
+/- \text { Suggestive physical examination } \\
+/- \text { Contact with a case of pulmonary tuberculosis }\end{array}$} & \multirow{2}{*}{$\begin{array}{l}\text { Antibiotics } \times 2 \text { weeks } \\
\text { Poor/no response }\end{array}$} \\
\hline $\begin{array}{l}\text { Confirmed tuberculosis } \\
M \text { tuberculosis smear/culture } \\
\text { Positive disease }\end{array}$ & $\begin{array}{l}\text { Probable tuberculosis } \\
\text { Suggestive chest radiograph } \\
\text { Positive tuberculin test } \\
\text { Suggestive histology }\end{array}$ & \\
\hline \multirow[t]{4}{*}{$\begin{array}{l}\text { Start antituberculosis treat- } \\
\text { ment } \times 6 \text { months }\end{array}$} & $\begin{array}{l}\text { Start antituberculosis } \\
\text { treatment } \times 6 \text { months }\end{array}$ & $\begin{array}{l}\text { Start a trial of tuberculosis } \\
\text { treatment } \times 1 \text { month }\end{array}$ \\
\hline & Improved & Not improved \\
\hline & & Reassess \\
\hline & & Other diagnosis \\
\hline
\end{tabular}

body secretions and/or tissues confirms the diagnosis. Table 1 shows the diagnostic pathways for children with suspected pulmonary tuberculosis used at Lusaka UTH.

\section{Difficulties in diagnosis}

Diagnosis of paediatric tuberculosis on clinical evidence is difficult particularly in infants and small children in whom the disease is often non-specific. The following difficulties are usually encountered in developing countries.

\section{(1) TUBERCULOSIS INFECTION VERSUS DISEASE} - THE DILEMMA

Tuberculous infection implies that, though infection has taken place as is usually evidenced by a positive tuberculin skin test, the child is generally well without any clinical features suggestive of the presence of infection. In Zambia, as in most developing countries, BCG is given routinely at birth to all children (regardless of HIV status as long as the infant is not symptomatic) and use of tuberculin skin tests in this situation has therefore often not been helpful. Furthermore many children with disease remain asymptomatic for a long time and are only found if they are screened as contacts, which leads to delay in diagnosis.

\section{(2) ROLE OF TUBERCULIN SKIN TESTS}

The high prevalence of malnutrition coupled with high prevalence of parasitic and infective illnesses, including HIV infection, in developing countries further limit the use of the tuberculin test as a diagnostic tool of both tuberculosis infection and disease, as these conditions lead to immunosuppression. In a paediatric tuberculosis treatment evaluation study in Tanzania, a noted high frequency of tuberculin anergy after treatment $(60 \%)$ was attributed to overdiagnosis of the disease as the investigators had expected a comeback of tuberculin sensitivity in study children had they truly had tuberculosis. ${ }^{6}$

While a non-response to tuberculin skin testing might imply a real absence of infection or ongoing immunosuppression, it has been reported in apparently healthy children exposed to open tuberculosis cases and in children successfully treated for tuberculosis. ${ }^{7}$ The possibility of anergy should not however preclude skin testing. In adults with dual infection (tuberculosis and HIV) the frequency of a positive tuberculin test ranged from 33\% to $70 \%$ depending on the degree of immunosuppression. ${ }^{8}$ On the other hand a positive tuberculin test, particularly in a malnourished or immunosuppressed unvaccinated child becomes highly suggestive of probable tuberculosis.

Some workers have repeated the tuberculin test one to four weeks after the initial low response in anergic cases, while others, including the subcommittee of the joint tuberculosis committee of the British Thoracic Society recommend that anergic individuals be tested for at least two other recall antigens (that is Merieux Multitest). ${ }^{9} 10$ Experience of antigens that detect $M$ tuberculosis infection without depending on the integrity of host immune response is still limited.

False positive tuberculin tests have not been a problem in our experience. Table 2 gives a list of reasons for false negative and false positive tuberculin tests.

\section{(3) LIMITATIONS OF CLINICAL CRITERIA}

International and locally proposed clinical criteria for diagnosis of tuberculosis in children ${ }^{11-14}$ have sadly continued to lack uniformity and are not generally accepted, as demonstrated by a paucity of studies in the literature.

In a recent evaluation of the proposed World Health Organisation (WHO) criteria for diagnosis of pulmonary tuberculosis in children, $31 \%$ of proved tuberculosis cases would not have been classified as probable tuberculosis on clinical grounds. ${ }^{15}$

The WHOs tuberculosis scoring guidelines score a rapid response to a trial of antibiotics in a child suspected of having tuberculosis as -6 , while a child with bacteriological confirmation is given a score of $+7 .{ }^{13}$ One must therefore be careful when interpreting the score result, particularly in a child with tuberculosis as well as a superadded bacterial infection. On the other hand, non-response to antibiotics for a chronic respiratory illness could mean a nonmycobacteria infection such as Pneumocystis carinii, a fungal pneumonia, mycoplasma pneumonia, Kaposi's sarcoma, or lymphocytic interstitial pneumonitis, all of which might be HIV related.

At Lusaka's UTH, a diagnosis of probable tuberculosis is made in the presence of three or more of the following: (1) symptoms and signs of tuberculosis, (2) suggestive radiological findings, (3) lymph node or other biopsy tissue with caseation, (4) non-response to a two week course of antibiotics, (5) response to antituberculosis treatment, (6) history of close contact with a tuberculosis case, and (7) a positive

Table 2 Reasons for false negative and false positive tuberculin skin tests

\begin{tabular}{ll}
\hline False negative & False positive \\
\hline Malnutrition & Wrong injection technique \\
HIV infection & Overdosage \\
Malaria & Contaminants in test material \\
Malignancy & Atypical mycobacteria \\
Immunosuppressive drugs & \\
\hline
\end{tabular}


Table 3 The Papua New Guinea paediatric tuberculosis score chart (courtesy of Dr Keith Edwards, University of Papua New Guinea)

\begin{tabular}{|c|c|c|c|c|}
\hline Feature & 0 & \multicolumn{2}{|l|}{1} & 3 \\
\hline $\begin{array}{l}\text { Length of illness } \\
\text { Nutrition (weight) } \\
\text { Family tuberculosis } \\
\text { past or present }\end{array}$ & $\begin{array}{l}\text { Less than } 2 \text { weeks } \\
\text { Above } 80 \% \text { for age } \\
\text { None }\end{array}$ & \multicolumn{2}{|c|}{$\begin{array}{l}2-4 \text { weeks } \\
\text { Between } 60 \% \text { and } 80 \% \\
\text { Reported by family }\end{array}$} & $\begin{array}{l}\text { More than } 4 \text { weeks } \\
\text { Less than } 60 \% \\
\text { Proved sputum } \\
\text { positive }\end{array}$ \\
\hline $\begin{array}{l}\text { Score of other features } \\
\text { Positive tuberculin te } \\
\text { Large painless lymph } \\
\text { groin } \\
\text { Unexpected fever, nig } \\
\text { treatment } \\
\text { Malnutrition, not imp } \\
\text { Angle deformity of sp } \\
\text { Joint swelling, bone } \\
\text { Explained abdominal } \\
\text { Central nervous syste } \\
\text { (send to hospital, if }\end{array}$ & $\begin{array}{l}\text { odesent } \\
\text { odes, firm, soft, sinus } \\
\text { sweats, no response } \\
\text { oving after } 4 \text { weeks } \\
\text { e } \\
\text { elling, or sinuses } \\
\text { lass or ascites } \\
\text { change in temperatur } \\
\text { ossible) }\end{array}$ & $\begin{array}{l}\text { neck axilla, } \\
\text { malaria }\end{array}$ & $\begin{array}{l}2 \\
3 \\
4 \\
3 \\
3 \\
3\end{array}$ & \\
\hline
\end{tabular}

When score is 7 or more treat for tuberculosis

tuberculin test. The symptoms and signs of tuberculosis and the suggestive radiological findings are as stated above under conventional diagnosis. The Lusaka UTH criteria, like all the other scoring criteria, miss a significant number of diseased children because of being suited for use in children with advanced disease. On the other hand, in most developing country hospital settings there is a high risk of overdiagnosis because of the increased prevalence of children with protein energy malnutrition with or without underlying HIV infection. The Papua New Guinea tuberculosis scoring scheme (table 3 ), though having the same disadvantages as the other scoring systems, has the advantage of not needing any radiological and/or bacteriological backup services. ${ }^{14}$

\section{(4) COLLECTION OF SPECIMENS FROM} CHILDREN

Although paediatric tuberculosis has a propensity for extrapulmonary disease, pulmonary tuberculosis is the most common manifestation in non-HIV infected children. ${ }^{4}$ Unfortunately younger children rarely expectorate sputum and even when obtained it is frequently negative on smear and/or culture. ${ }^{11} 16$ Special expertise and an aggressive approach to obtaining specimens from children (sputum/gastric washings) may improve culture yields but only marginally. ${ }^{16}$

The percentage of paediatric positive acid fast bacilli specimens (smear/culture) at Lusaka's UTH in 1992 was 13\%. Smear/culture positive paediatric specimens have ranged from $0.9 \%$ to $57 \%$ depending on age, number of obtained specimens, disease severity, and to a lesser extent prevalence of tuberculosis. ${ }^{511} 16$ Stool microscopy and culture for $M$ tuberculosis has been used in diagnosing pulmonary tuberculosis especially where sputum or gastric washings cannot be obtained. Yields tend to be lower than for sputum and/or gastric washings and may even be negative when gastric aspirates have been positive. ${ }^{17}$ On the other hand they tend to be higher when there is associated gastrointestinal tuberculosis.

(5) CHEST RADIOGRAPHY

Radiological findings do not always help, particularly in small children, and can at times be confusing, as some cases show extensive disease even when clinical examination has revealed little or nothing. The picture becomes more confused when there is superadded bacterial pneumonic findings in addition to those of tuberculosis. In HIV infected children some of the infections they are prone to have similar radiological findings as in tuberculosis adding on to the difficulties.

\section{(6) COST OF DIAGNOSIS}

Because of the lack of a definitive diagnostic tool, the dependence on multiple diagnostic criteria makes paediatric tuberculosis diagnosis an expensive venture. It becomes even more so in early disease when symptoms are nonspecific.

The cost of diagnosis per patient at Lusaka's UTH has been estimated to be about K20 000 (US\$30), inclusive of one plain chest radiograph, three gastric washings or sputum specimens for microscopy, culture and sensitivity, and at least one plain chest radiograph of a family member considered to be the source. This cost does not take into account the cost of manpower needed. In the past, Zambian patients have not had to pay for investigative procedures at hospitals but they may soon need to do so as part of the Ministry of Health's cost sharing scheme. This means that patients or their parents may in future have to make decisions about which tests should be carried out depending on their ability to pay, which would further underscore the ability of health workers to making the proper diagnosis.

In developing countries the problems of diagnosing tuberculosis in children are compounded by the heavy patient workload coupled with staff shortages and inadequate facilities. Some health facilities do not have a microscope let alone radiological and/or tuberculin testing facilities. Furthermore, transport problems often result in contamination of specimens sent to diagnostic centres. ${ }^{11}$

\section{Increased diagnostic difficulties caused by the HIV epidemic}

The challenge of diagnosing paediatric tuberculosis faced for a long time by paediatricians has now been complicated by the HIV epidemic. The WHO's clinical case definition of AIDS among adults with tuberculosis was not specific enough to predict which tuberculosis cases were HIV positive. ${ }^{18}$ The same may be true for children with dual disease. Furthermore, unlike in developed countries, in developing countries the diagnosis of HIV infection in children under 15 months in itself is difficult because of a lack of access to viral culture facilities and newer diagnostic techniques such as HIV polymerase chain reaction, specific HIV-IgA and p24 antigen acid dissociation test. This is important considering the high number of suspected tuberculosis cases in this age group.

Experience of the epidemiology and natural history of tuberculosis in HIV infected children is still too poor to allow an improved clinical 
Table 4 Paediatric probable tuberculosis admissions, deaths, and corresponding HIV seroprevalence rates at UTH, Lusaka (1989-1993)

\begin{tabular}{llrl}
\hline Year & $\begin{array}{l}\text { No of } \\
\text { admissions } \\
\text { (per 1000)* }\end{array}$ & $\begin{array}{l}\text { No (\%) } \\
\text { hospital } \\
\text { deaths }\end{array}$ & $\begin{array}{l}\text { HIV } \\
\text { seroprevalence } \\
(\%)\end{array}$ \\
\hline 1989 & $285(18 \cdot 6)$ & $55(19 \cdot 3)$ & $24 \cdot 0$ \\
1990 & $292(20 \cdot 1)$ & $53(18 \cdot 2)$ & $37 \cdot 0$ \\
1991 & $480(27 \cdot 6)$ & $87(18 \cdot 1)$ & $55 \cdot 8$ \\
1992 & $509(24 \cdot 1)$ & $129(25 \cdot 3)$ & $60 \cdot 9$ \\
1993 & $437(25 \cdot 7)$ & $84(19 \cdot 2)$ & $>70 \cdot 0$
\end{tabular}

^Per 1000 total paediatric admissions.

†Probable tuberculosis case fatality rate.

criteria for diagnosis of tuberculosis in suspected cases. Moss et al of the Harlem Hospital Centre, New York have recently reported their experience with tuberculosis in five HIV infected children. ${ }^{19}$ The cases demonstrated a wide variability of clinical manifestations similar to those seen in non-HIV infected children, with an age range of 6 months to $7 \cdot 8$ years. All the children belonged to ethnic minority groups and contact screening identified adult bacillary sources in four children; two were diagnosed as having HIV infection at the same time as that of tuberculosis and four had culture positive tuberculosis including one with multiple drug resistant $M$ tuberculosis.

In Zambia, Chintu et $a l^{20}$ and Bhat et al (unpublished) have also reported their experience of tuberculosis in HIV infected children. Most of the cases resembled adult or reactivation type of disease with cavitary lesions, extensive pneumonias, and dissemination.

The $M$ tuberculosis smear positive rate from sputum/gastric washings among the seropositive children was $6.4 \%$ (eight out of 126) compared with $34.6 \%$ in 81 HIV negative children with probable tuberculosis (G J Bhat, unpublished). Four out of the six smear positive children with dual disease who completed treatment responded well to treatment. In contrast, only $17(20 \%)$ out of 84 smear negative HIV positive children who completed treatment responded well to treatment. It is possible that some smear negative children may not have had tuberculosis at all. Postmortem studies in the Ivory Coast indicate that tuberculosis in children with HIV is less common than previously thought. ${ }^{21}$

Unlike the situation in the community and at first level health facilities (that is rural and urban health centres), probable tuberculosis is overdiagnosed in hospitals in developing countries because many hospitalised children have either HIV disease and/or pulmonary symptoms not responding to ordinary antibiotics. The observed progressive rise over the years in HIV seroprevalence in hospitalised children with suspected tuberculosis at UTH may therefore be a mere reflection of an increase in paediatric HIV disease over the years. Table 4 shows the number of probable tuberculosis admissions and deaths to Lusaka's UTH paediatric service and the corresponding HIV seroprevalence rates from 1989 to 1993.

Given the expected increasing numbers of adults with dual disease (HIV and tuberculosis) and the fact that diagnosis of paediatric tuberculosis depends mainly on the epidemiological context, the difficulties in confirming adult cases will also render paediatric diagnosis less secure. Diagnosis of tuberculosis in HIV infected adults is proving to be just as difficult as that in paediatric tuberculosis because of the paucibacillary nature of the disease. The inability, therefore, to discover adult bacillary sources in households of children under investigation of tuberculosis is expected to further underscore the true incidence of paediatric tuberculosis. In addition, the role of HIV infected adults with pulmonary tuberculosis, as well as the importance of adult sputum positivity on culture only, in spreading infection among child contacts is at present uncertain.

\section{Other methods for diagnosis of tuberculosis}

Many non-culture methods including serological and biochemical techniques have been employed for diagnosis of tuberculosis in children. Unfortunately with the exception of the Indian subcontinent, experience of these methods in developing countries is limited. Where they have been used, the methods have to date failed to reach clinical significance.

\section{(1) SEROLOGY}

Serological tests have included enzyme linked immunosorbent assays for detecting antibodies to purified protein derivative $M$ tuberculosis antigen 5, $M$ tuberculosis strain H37 RV, and adsorbed mycobacterial sonicates. ${ }^{22} 23$

\section{(2) BIOCHEMISTRY}

Biochemical tests have included detection of tuberculostearic acid in the cerebrospinal fluid and serum gluteraldehyde. ${ }^{24}$

\section{(3) POLYMERASE CHAIN REACTION AND DNA FINGERPRINTING}

While the use of the polymerase chain reaction for diagnosis of tuberculosis could provide the needed non-invasive and rapid diagnostic tool for both paediatric and HIV associated adult paucibacillary pulmonary tuberculosis, ${ }^{25}$ it is still in its early stages of development and currently beset by problems of reproducibility and contamination.

Specimens that might be suitable for the polymerase chain reaction include sputum, bronchial or gastric washings, pleural, pericardial and peritoneal effusions, cerebrospinal fluid, blood, tissue biopsies or aspirates, saliva, stool, and urine. ${ }^{25}$ The latter three would be particularly useful in infants and young children in whom it is difficult to obtain suitable specimens.

A polymerase chain reaction facility has recently been established at Lusaka's UTH, and one of the specific objectives of the facility is to compare it with current diagnostic strategies for paediatric tuberculosis, including meningitis. The department of paediatrics at UTH is currently carrying out a study on 
diagnosis of paediatric tuberculosis in which various criteria including clinical, radiological, bacteriological, and the polymerase chain reaction will be assessed. This study will not assess any of the immunological and/or biochemical tuberculosis tests, but sera will be stored for future reference.

Unlike the polymerase chain reaction, DNA fingerprinting of cultured $M$ tuberculosis, which can now also be done at the UTH, could in contact studies contribute to a better understanding of the dynamics of transmission of adult tuberculosis to children because of the potential to correctly identify source cases. DNA fingerprinting might also resolve issues concerning the increasing occurrence of pneumonia in infants of HIV infected mothers that is being observed at the UTH, and which responds to antituberculus drugs, and whether it is due to $M$ tuberculosis or BCG.

\section{Public health impact of tuberculosis in children}

Because of the limited infectivity, tuberculosis in children is not expected to have a major impact on the overall epidemiological situation. It is, however, important to note that if a child is sputum/gastric washing positive, he or she may be as infective as an adult particularly if it is an older child who is coughing. The continued occurrence of tuberculosis in children not only implies ongoing transmission of infection from adults to children of all age groups, but is in part a reflection of failed tuberculosis control efforts and a harbinger of continued risk to all.

Epidemiological background concerning risk of exposure to infected adult sources is important in establishing the diagnosis of tuberculosis in children. This often leads to treatment of the source adult cases thereby reducing risk of tuberculosis to other siblings in the household. Child contacts of adult index cases, however, tend not to benefit from case finding exercises because of difficulties in establishing diagnosis of tuberculosis infection and/or disease and the assumption that children are at a reduced risk of tuberculosis infection because of their age and BCG vaccination. In Zambia a case-control study of the impact of HIV on tuberculosis in children revealed a BCG efficacy rate of $55 \% .^{26}$

High BCG coverage rates in developing countries have in part contributed to the public, and most health workers, being complacent about the occurrence of tuberculosis in children. Consequently, missed opportunities for providing tuberculosis chemoprophylaxis to children at risk are common.

\section{Conclusion}

Failure to confirm a diagnosis of tuberculosis in the majority of paediatric suspected cases has not only underscored the importance of the disease in children but has been a major constraint in paediatric tuberculosis research including epidemiology, pathogenesis, treatment, and chemoprophylaxis. Certainly, the true incidence as well as trends of morbidity and mortality will continue to remain unknown unless a more useful definitive diagnostic tool and/or criteria is found. In addition, studies of tuberculosis in children that include large proportions of children with unconfirmed disease are likely to render the results unreliable and consequently difficult to base policy on.

The increase in morbidity and mortality due to tuberculosis has been increased by the HIV epidemic. Given the debatable efficacy of BCG, ${ }^{27}$ the fact that children constitute close to $50 \%$ of the population in most developing countries, and that both the HIV and tuberculosis epidemics are, at least in developing countries, expected to continue, there is a need to increase efforts of developing more reliable methods for diagnosing paediatric tuberculosis infection and/or disease.

1 Stark JR. Multiple drug therapy for tuberculosis in children. Pediatr Infect Dis $\mathcal{F} 1990 ; 9: 785-91$.

2 Government of the Republic of Zambia. Bulletin of Health statistics 1987-1988 and major health trends 1978-1988. statistics 1987-1988 and major health trends 1978-1988. December 1990.

3 Bhat GJ, Luo C, Osborne CM, et al. Impact of HIV-I infection on childhood morbidity and mortality in Lusaka, Zambia. Proceedings of the IXth International Conference on AIDS, IVth STD World Congress. Berlin, June 6-11, 1993: abstr No PO B37-2378.

4 Snider DE Jr, Rieder HL, Gombs D, Bloch AB, Hayden $\mathrm{CH}$, Smith M. Tuberculosis in children. Pediatr Infect Dis f1 1988; 7: 271-8.

5 Stark JR, Taylor-Watts KT. Tuberculosis in the paediatric population of Houston, Texas. Pediatrics 1989; 84: 28-34.

6 Van De Hombergh J, Gebhrd AC, Voorhoeve HWA Tuberculosis in children: treatment evaluation and results Tuberculosis in children: treatment evaluation and results in a 5 year cohort of children with tuberculosis in Turian

Hospital, Tanzania. East Afr Med F 1991; 68: 686-93. Steiner P, Rao M, Victoria MS, et al. Persistently negative tuberculin reactions. $A m$ F Dis Child 1980; 134: 747-50.
Reider HL, Caunthen GM, Bloch AB, et al. Tuberculosis and acquired immunodeficiency syndrome: Florida. Arch and acquired immunodeficiency

9 Thomson NJ, Glasroth JL, Snider DE Jr, Farer LS. The booster phenomenon in serial tuberculin testing. Am Rev Respir Dis 1979; 119: 589-97.

10 Guidelines on the management of tuberculosis and HIV infection in the United Kingdom. Education and debate. Subcommittee of the Joint Tuberculosis Committee of the British Thoracic Society. BMF 1992; 304: 1231-3

11 Cundall DB. The diagnosis of pulmonary tuberculosis in malnourished Kenyan children. Ann Trop Pediatr 1986; 6: 249-55.

12 World Heath Organisation. Provisional guidelines for the diagnosis and classification of the EPI target diseases for primary health care. Geneva: WHO, 1983. (EPI/GEN/83/4.)

13 Tidjani O, Amedone A, ten Dam HG. The protective effect of BCG vaccination of the newborn against childhood tuberculosis in an African community. Tubercle 1986; 67: tuberculosis

14 Crofton J, Horne N, Miller F. Clinic tuberculosis. London and Basingstoke: Macmillan Education, 1992.

15 Gie RP, Beyers N, Schaaf HS, et al. Evaluation of criteria for diagnosis of pulmonary $\mathrm{TB}$ in children living in a developing country. Proceedings of the World Congress on Tuberculosis. Bethesda, MD, Nov 16-19, 1993: abstr No $25 \mathrm{D}$

16 Scientific Committee of the IUATLD. Tuberculosis in children. Guidelines for diagnosis, prevention and treatment. Bulletin of the International Union of Tuberculosis and Lung Diseases 1991; 66: 61-70.

17 Donald PR, Schaaf HS, Gie RP, Beyers N, Nand Sirgel F. Stool microscopy and culture to aid the diagnosis of pulmonary tuberculosis. Proceedings of the World Congress pun Tuberculosis. Bethesda, MD, Nov 16-19, 1993: abstr No 25A.

18 Perriens JH, Mukadi Y, Nunn P. Tuberculosis in HIV infection: implications for Africa. AIDS 1991; 5 (suppl): infection:

19 Moss WJ, Dedyo T, Suarez M, Nicholas SW, Abrams E. Tuberculosis in children infected with human immunodeficiency virus; a report of 5 cases. Pediatr Infect Dis deficiency virus;

20 Chintu C, Bhat GJ, Luo C, et al. Fatal skin reactions in children treated for TB in Zambia. Proceedings of the VIII children treated for TB in Zambia. Proceedings of the VIII International Conference on AIDS/II STD Con
Amsterdam, July 19-24, 1992: abstr No POB 3859.

21 Lucas SB, Hounnou A, Koffi K, Beaumel A, Andoh J, De Cock, KM. The pathology of paediatric HIV infection in Cote D'Ivoire. F Pathol 1993: abstr No 29. 
22 Hussey G, Kibel M, Dempster W. The serodiagnosis of tuberculosis in children: an evaluation of an Elisa test using $1 \mathrm{gG}$ antibodies to $M$ tuberculosis strain $\mathrm{H} 37 \mathrm{RV}$. Ann Trop Paediatr 1991; 11: 113-8.

23 Alde SL, Pelosi FR, Budan HF, Palma Beltran OH, Gonzalez-Montaner LJ. The evaluation of an enzyme linked immunoadsorbant essay (ELISA) using an IgG antibody to $M$ tuberculosis antigen 5 in the diagnosis of active tuberculosis in children. Am Rev Respir Dis 1989; 139: 748-51.

24 Grange JM. New approaches to diagnosis of TB in 45 children with special reference to neurotuberculosis. Ind $\mathcal{F}$ Pediatr 1990; 57: 639-44.

25 Wilson SM, McNerny RM, Nye PM, Godfrey-Faussett $P$ Stoker NG, Voller A. Progress towards a simplified polymerase chain reaction and its application to the diagnosis of tuberculosis. F Clin Microbiol 1993; 31: 776-82.

26 Bhat GJ, Diwan VK, Chintu C, Kabika M, Masona J. BCG provides no protection in HIV positive children: a cas control study. F Trop Pediatr 1993; 39: 219-23.

27 Fine PEM. BCG vaccination against tuberculosis and leprosy. Br Med Bull 1988; 44: 691-703. 